Mate retention strategies, self-esteem, mate value and facial attractiveness disparity in Brazil and in the UK

Shortened title: Mate retention strategies and self-evaluation in Brazil and in the UK

Bruna S Nascimento*

Anthony C Little

University of Bath

*Corresponding author: b.da.silva.nascimento@bath.ac.uk 


\title{
Mate retention strategies, self-esteem, mate value and facial attractiveness disparity in Brazil and in the UK
}

\begin{abstract}
This study compared mate retention strategies (MRS) in Brazil and in the UK, testing whether culture moderates the association between MRS and self-evaluated variables (e.g. mate value). Our findings demonstrated that women's MRS varied crossculturally, with Brazilian women reporting to perform MRS more often than British women. Men's MRS did not vary between cultures. Additionally, culture moderated the association between MRS frequency and facial attractiveness disparity (the difference in attractiveness between partners) and mate value. This study presents initial evidence on the influence of culture on the frequency of MRS and its role in the association between self-evaluation and strategies designed to retain a partner.
\end{abstract}

Key-words: mate retention; romantic relationships; cultural differences; mate value.

\section{Introduction}

Long-term relationships provide several benefits for humans, including reproductive advantages, such as sexual reproduction and a pair-bonding for the rearing of offspring, and secondary adaptive benefits, such as social support, mutual sharing and protection (Kenrick \& Trost, 2004; Næss, Blekesaune, \& Jakobsson, 2014). To preserve long-term relationships, avoid infidelity by their partners and prevent relationship dissolution, individuals use specific tactics called mare retention strategies (MRS; Barbaro, Pham, \& Shackelford, 2015; Buss, 1988; Buss \& Shackelford, 1997; Davies \& Shackelford, 2017). MRS range from positive actions, such as appearance enhancement (Pham \& Shackelford, 2013; Pham, Shackelford, \& Sela, 2013), and copulation (Barbaro, Pham, \& Shackelford, 2015), to negative behaviours, such as violence against the partner and/or same-sex rivals (Buss, 1998; Buss \& Duntley, 2013). Buss (1998) identified 19 types of MRS that were grouped into five broader categories: direct guarding (e.g., vigilance), intersexual negative inducements (e.g., emotional manipulation), positive inducements (e.g., love and care), public signs of possession (e.g., verbal signs of 
possession), and intrasexual negative inducements (e.g., threat of rivals). Thus, some MRS operate by inflicting costs on the partner or rivals (e.g. direct guarding, intrasexual negative inducements), whereas others operate by providing benefits to the partner (e.g. positive inducements, public signs of possession).

Important variables that are associated with the deployment of MRS include: (1) the relative value of the mate; (2) the discrepancy between members of the couple in their relative "mate value"; and (3) the perceived probability of infidelity or defection (Buss \& Shackelford, 1997). Specifically, positive inducements and public signals of possession have been found to be positively correlated with a person's own mate value, whereas strategies such as direct guarding and intrasexual negative inducements were found to be negatively associated with own mate value (Salkicevic, Stanic, \& Grabovac, 2014). Higher discrepancies between the partners in age and physical attractiveness also increase the frequency of a person's mate retention performance in both men and women, as well as their experience of jealousy (Buss \& Shackelford, 1998; Sidelinger \& Booth-Butterfield, 2007).

In addition, studies have also demonstrated that self-esteem influences perception of infidelity (Zeigler-Hill, Fulton \& McLemore, 2012). Individuals at risk of partner infidelity are more likely to engage more often in MRS (Starrat, Shackelford, Goetz, \& McKibbin, 2007). Self-esteem can also predict mate retention tactics, such that lower self-esteem results in higher frequency of MRS (Holden et al., 2014). Gender also affects the expression of MRS. For example, men use strategies such as resource display, dominance, intrasexual threat, sexual inducements and possessive ornamentation more often than women. On the other hand, women are more likely to enhance their appearance to maintain their partnerships, be vigilant of them, and are more prone to punish infidelity than men (Buss, 1988; Miguel \& Buss, 2011). 
Similar to other evolved psychological mechanisms, MRS are likely to be sensitive to varying contexts. Although no studies that specifically compared MRS between cultures were found, previous research has provided evidence of cultural variation in jealousy, which is also a mechanism to avoid infidelity. For example, comparing the expression of jealousy in four nations, India, Ireland, Thailand, and the United States (US), Croucher et al. (2012) found that American, Indian and Irish participants express more emotional and behavioural jealousy than Thai participants. Buunk, Angleitner, Oubaid, and Buss (1996) found support for a hypothesis derived from evolutionary psychology across the US, Germany, and the Netherlands, that women exhibit greater psychological distress towards emotional than sexual infidelity, whereas men express higher psychological distress in face of sexual than emotional infidelity across all countries. The magnitude of the sex differences, however, depended on the cultural context: the size of the difference was larger in the US than in Germany and the Netherlands. Despite similarities between cultures, the cultural context seems to play an important role in the specific strategies chosen to protect a relationship. Thus, in the present study aimed to examine if MRS differ between cultures and test whether MRS are differently associated with self-esteem, mate value, and facial attractiveness disparity.

Most studies on MRS have been conducted using US-American samples (see Pollet \& Saxton, 2018). It is then important to sample participants from non-Western countries. Specifically, this study sought to investigate the influence of personal variables (e.g. self-esteem) on MRS in Brazil and in the United Kingdom (UK). Brazilians are slightly more sexually restricted in comparison to the British (Schmitt, 2004). There are also some variations between the two countries in romantic attachment styles (Schmitt et al., 2004), such that Brazilians present lower levels of secure 
attachment, and higher levels of preoccupied and fearful attachment than British people. Higher levels of insecure attachment are usually found in more stressful and environmentally demanding contexts (Schmitt, 2005). This is because individuals in more demanding environments tend to invest more in their relationships and individuals higher in anxious attachment perform MRS with greater frequency (Barbaro, Pham, Shackelford, \& Zeigler-Hill, 2015). Therefore, we hypothesised that individuals in Brazil would perform MRS more often than those in the UK.

Extending previous research showing that the association between infidelity concerns, jealousy, gender, and partner's facial attractiveness vary between cultures (Buunk et al., 1996; Dillon et al., 2014), we also examined whether the impact of these variables on MRS differs between Brazil and the UK. In sum, this study aimed to: (1) determine if MRS frequency varies between Brazil and United Kingdom, and (2) examine if the association between MRS and (a) self-esteem, (b) mate value and (c) perceived facial attractiveness disparity varies across the two samples.

\section{Method}

\section{Participants}

British sample. One hundred and seventy-six people who reported to be born in the UK participated in this study, of which $72.2 \%$ were female, aged between 18 and 56 years old $(M=22.93 ; S D=6.78)$. The relationship length mean was 33.31 months $(\mathrm{SD}=$ 45.13).

Brazilian sample. Two hundred and six people who reported to be born in Brazil participated in this study, of which $76.7 \%$ were female, aged between 18 and 49 years old $(M=26.20 ; S D=6.02)$. The relationship length mean was $61.09(\mathrm{SD}=65.95)$.

Because this is a gender-imbalanced sample and gender affects MRS, and considering that our main focus is on cultural differences rather than gender differences, 
we split the data into a female and male sample to prevent potentially biased results. Our final female sample consisted of 285 participants, of which $55.4 \%$ were Brazilian, whereas our male sample was composed by 97 males, of which $49.5 \%$ were Brazilian.

\section{Materials}

Besides demographic questions, participants completed the following instruments.

Mate Retention Inventory (Short-Form) - MRI-SF (Buss, Shackelford, \& McKibbin, 2008). The MRI-SF is composed of 38 items that assess 19 tactics of mate retention, that form five broader categories: Direct Guarding (e.g. snooped through my partners personal belongings; Insisted that my partner spend all her/his free time with me), Intersexual Negative Inducements (e.g. showed interest in another women/men to make my partner angry; told my partner that was dependent on my partner), Positive Inducements (e.g. bought my partner an expensive gift; displayed greater affection for my partner, Public Signs of Possession (e.g. bragged about my partner to other men/women; held my partner's hand when other women/men were around), Intrasexual Negative Inducements (e.g. stared coldly at a man/woman who was looking at my partner; slapped a man/woman who made a pass at my partner). Participants indicate how often they performed each behaviour within the past year, using a scale varying from 0 (never) to 3 (often performed this act). In Brazil, a Brazilian version of this instrument was used to collect data (Lopes, Shackelford, Santos, Farias, \& Segundo, 2016). Regarding the reliability of the instruments, the Brazilian (Crobanch's alphas ranging from .50 to .71 ) and British (Crobanch's alphas ranging from .54 to .77 ) version presented suitable indices of internal consistency for each of the five categories. 
Rosenberg's Self-esteem Scale (Rosenberg, 1965). This instrument was used to evaluate global self-esteem using ten self-descriptive statements (e.g. "On the whole, I am satisfied with myself”, “At times, I think I am no good at all”), answered on a four-point Likert scale ranging from 1 (Strongly agree) to 4 (Strongly disagree). The English and Brazilian (Hutz \& Zanon, 2011) versions showed a high degree of internal consistency $(\alpha=.86, \alpha=.87$, respectively).

Self-Perceived Mating Success Scale (Landold, Lalumiere, \& Quinsey, 1995). The scale assesses individuals' perception of the reactions they receive from members of the opposite-sex (e.g. "Members of the opposite sex notice me", "Members of the opposite sex are attracted to me") and functions as a mate value measure. Responses were given on a 7-point scale ranging from 1 (Strongly disagree) to 7 (Strongly agree). Regarding the internal consistency the eight items scale achieved a suitable value in Brazil $(\alpha=$ $.75)$ and in the UK $(\alpha=.86)$

Perceived facial attractiveness disparity. To measure perceived discrepancy between the own facial attractiveness and the perceived facial attractiveness of one's partner, participants were asked to answer two questions evaluating self-perceived facial attractiveness (How attractive do you think your face is?) and perceived partner's facial attractiveness (How attractive do you think your partner's face is?) on a seven-point scale, ranging from 1 (Not attractive at all) to 7 (Extremely attractive). Perceived facial attractiveness disparity was then calculated by subtracting the perceived partner's facial attractiveness from the own facial attractiveness. Higher scores describe individuals that perceive their partners as more attractive in comparison to themselves. The higher this score, the higher the discrepancy between one and one's partner. 


\section{Procedure}

Participants in Brazil were recruited online through social networks (e.g. Facebook) and through a university recruitment system in the UK. The study was conducted online through Qualtrics survey software. First, participants read a participant information sheet, detailing the procedure, confidentiality of data, and the possibility of withdrawing any time were explained. After giving their informed consent, participants were redirected to a new page containing the questionnaires. Participants in the United Kingdom answered all the measures in English, while Brazilian participants answered in Brazilian Portuguese. Brazilian adapted versions of part of the questionnaires such as the MRI and Rosenberg's self-esteem scale are already available in the literature. Mmeasures where a Brazilian version was not available were translated using backtranslation procedures by two bilingual psychologists. After completing all the measures, participants were debriefed and thanked.

\section{Data analysis}

In order to test the differences in the frequency of MRS between Brazil and the United Kingdom, a mixed model ANOVA was performed, including the categories of mate retention (direct guarding, intersexual negative inducements, positive inducements, public signs of possession and intrasexual negative inducements) as the within-subject variables and nationality (Brazilian or British) as a between-subject variable. To test whether nationality moderated the association between MRS and self-esteem, we conducted separated ANCOVAs, using a customized model to test the extent to which the association between MRS and self-esteem, mate value and facial attractiveness disparity varies according to the nationality. All statistical analyses were carried out using SPSS (version 21). 


\section{Results}

MRS in Brazil and in the UK

A 2 (nationality) x 5 (MRS) ANCOVA was performed to compare MRS between Brazil and United Kingdom, controlling for relationship length. Among men, the interaction between nationality and MRS was not-significant, $F(3,258)=1.08, p=.35$, which means that the frequency of strategies that British and Brazilian men use were not significantly different (see Annex I). A significant interaction between nationality and MRS was found in our female sample, $F(4,267)=10.68, p<.001, \eta_{\mathrm{p}}^{2}=.14$.

Specifically, as seen in Figure 1, Brazilian women reported to perform Direct guarding $(M=1.65, S D=.49)$, Intersexual Negative Inducements $(M=1.93, S D=.43)$, Positive Inducements $(M=2.86, S D=.43)$, Public Signs of Possession $(M=2.30, S D=.50)$, and Intrasexual negative inducements $(M=1.44, S D=.40)$ more often than the British women (respectively $M=1.33, S D=.38 ; M=1.52, S D=.40 ; M=2.70, S D=.37 ; M=$ $2.18, S D=.47 ; M=1.28, S D=.28)$.

[Insert Figure 1 here]

Exploring the association between self-evaluation variables and MRS in Brazil and in the UK

Before testing whether culture moderates the association between self-evaluation variables and MRS, we explored the correlational patterns in both countries separately again splitting the sample for gender. For this analysis, correlations between MRS and self-evaluation variables (self-esteem, mate value, and facial attractiveness disparity) were carried out, first in the male sample. As can be seen in Table 1, among British participants (superior diagonal), a significant correlation between public signs of possession and mate value was observed $(r=-.29 ; p=.048)$ (controlling for age and 
relationship length does not change the correlation patterns), which means that those men who perceived themselves to be more successful with the opposite sex tend to use less often strategies that show they are together with their partners. In Brazil, on the other hand, only a correlation between intrasexual negative inducements and facial attractiveness disparity was observed $(r=-.39 ; p=.01)$ (controlling for age and relationship length does not change the correlation patterns). When Brazilian men believe their partners are more attractive, they were less likely to direct strategies towards men to protect their relationships.

\section{[Insert Table 1 here]}

Among women from the UK, significant associations of positive inducements with mate value $(r=.23 ; p<.01)$ and attractiveness disparity $(r=-.20 ; p<.05)$ were found. Public signs of possession correlated negatively with self-esteem $(r=-.19 ; p<$ $.05)$ and attractiveness disparity $(r=-.25 ; p<.01)$. In turn, intrasexual negative inducements correlated with mate value $(r=.17 ; p<.05)$ and attractiveness disparity $(r$ $=.27 ; p<.05$ ). In Brazil, no significant associations were found (see Table 2). Thus, those British women who think of themselves as valuable partners are more likely to show love and care for their partners, and to use negative strategies directed to potential rivals. Higher self-esteem seems to prevent engaging in tactics to show a public commitment. However, when British women perceive their partners are more attractive, they use positive strategies less often and opt for engaging in behaviours targeting potential rivals. 
Tables 1 and 2 show that the correlation patterns vary between Brazil and the UK, however, final conclusions on how culture moderates the association between MRS and the variables of interest cannot be drawn only based on correlations.

\author{
[Insert Table 2 here]
}

\title{
MRS, self-esteem, mate value, and facial attractiveness: culture as a moderator
}

We performed several ANCOVAs using a customised model to test for an interaction effect of nationality*self-esteem, nationality*mate value, and nationality*attractiveness disparity on MRS for each of the five different strategies listed previously. In men, all the interaction effects were non-significant (All F $<3$; All $p>.10$ ), except for the interaction between nationality and attractiveness disparity on intrasexual negative inducements, $F(1,81)=6.54 ; p=0.012 ; \eta_{\mathrm{p}}^{2}=.07$. The association of intrasexual negative inducements with facial attractiveness disparity was positive in British men, but negative in Brazil (see annex II).

In the female sample, a significant interaction was found between facial attractiveness and nationality on intersexual negative inducements, $F(274,1)=4.428, p$ $\left.=.036, \eta_{\text {partial }}^{2}=.02\right)($ see annex III). Specifically, the association between intersexual negative inducements and facial attractiveness disparity was positive in the UK, but non-significant in Brazil (see Table 2).

We also found a significant interaction of nationality and mate value on positive inducements, $\left.F(1,274)=6.293, p=.013, \mathrm{n}_{\mathrm{p}}^{2}=.02\right)$. The association is positive in the UK, but negative in Brazil (see annex IV).

Culture also moderated the association between intrasexual negative inducements and facial attractiveness disparity, $\left.\mathrm{F}(1,274)=3.766, p=.05, \eta_{p}^{2}=.01\right)$. In 
the UK, women who perceived their partner as more attractive, engaged more often in strategies directed to potential rivals. In Brazil, no association was found (see annex V).

\section{Discussion}

The present study compared MRS between Brazil and the United Kingdom. Moreover, the moderating influence of culture on the relationship between self-esteem, mate value, facial attractiveness disparity, and MRS was investigated. Although there are several cultural differences between the UK and Brazil regarding relationship context, including threat of mate poachers and reported sociosexuality levels (Schmitt et al., 2004), it is surprising that no differences were found in MRS between the countries in our male sample. However, consistent with our predictions, Brazilian women engaged more often in MRS in comparison to British women. Brazilian women reported using negative and positive inducements and strategies directed towards potential rivals more often than British women. A potential explanation for these results in women is that in South America, at least in comparison to Europe, the threat of mate poachers (i.e. individuals that try to attract someone's partner away from the relationship) is higher (Schmitt et al., 2004). Consequently, the possibility of infidelity or relationship dissolution is also higher. The perceived threat will activate jealousy (Daly, Wilson, \& Weghorst, 1982) that, in turn, results in MRS display. Additionally, in collectivist cultures like Brazil (Triandis, 2018), the establishment of a relationship has to meet the expectations of the family and other group members (Hatfield \& Rapson, 2006). This may increase the fear of not being able to engage in another equally or more valuable relationship in case the ongoing partnership ends, resulting in overprotection towards the relationship and expression of jealousy (Kemer, Bulgan, \& Yildiz, 2016). These arguments help to understand why, in comparison to the more individualistic UK (Hofstede, 1984), Brazilian women are more concerned about protecting their romantic relationships. 
Moreover, in a number of cases, culture moderated the relations between MRS and mate value, and facial attractiveness disparity. We found that the relationship between intrasexual negative inducements and facial attractiveness disparity varies across both countries in the male and female sample. British men and women who found their partner more attractive than themselves more often used behaviours such as derogation of mate and threats towards rivals, whereas among Brazilian men only, such perception leads them to engage less often in these sorts of tactics. In addition, among women only, culture moderated the association between facial attractiveness disparity and intersexual negative inducements. British women who found their partners more attractive engaged more often in behaviours such as jealousy induction and emotional manipulation. In contrast, facial attractiveness disparity was unrelated to these strategies among Brazilian women.

Our findings suggest that when British participants, regardless of their sex, perceive their partners as more attractive, they will try to maintain the relationship by performing both behaviours targeting their partners and potential rivals. Such results are consistent with previous findings in the USA, demonstrating that individuals who perceive their partner to be more attractive than themselves engage more often in both intrasexual and intersexual mate guarding strategies, involving negative and positive tactics (Oltmanns, Markey, \& French, 2017). Among British participants, higher mate value also was associated with greater frequency of positive inducements. More than the partner's perceived attractiveness level, for British women, their own value as a partner also accounts for the performance of positive strategies to preserve a relationship. In fact, mate value, including both one's own mate value as well as a perceived partner's mate value, were positively associated with the performance of positive inducements as a mate retention strategy (Miner, Starrat, \& Shackelford, 2009; Nowak \& Danel, 2014). 
Thus, it is possible that positive inducements may be more successful when performed by more attractive individuals in some contexts.

This study is not without limitations. One limitation of note is the nonprobability and convenience nature (i.e. non-random internet recruitment so participants are self-selected) of the sample, which can limit the generalizability of our findings. There is also the issue that our Brazilian sample was more heterogeneous than our British sample, which may increase generalizability for the Brazilian sample but also affect the results. For example, we did not control for the state of origin in Brazil, which may have affected our correlation patterns in this country. However, as an exploratory study, our initial findings provide some insights on how MRS may vary across countries. Another limitation is the use of self-report measures, which are subject to social desirability and may have an influence on participants' honesty to admit the performance of negative MRS. For example, participants will be less likely to admit that they have slapped someone else's face to protect their relationships against threats. A third limitation is the gender-imbalanced sample that did not allow for comparisons across genders, since sex it is an important factor when it comes to mate retention. Nevertheless, these factors do not invalidate our results. Regardless of gender, culture seems to play a role in the association between self-esteem variables and mate guarding.

Furthermore, it is important to consider that a number of variables, not explored in this study, could be driving the differences found between the UK and Brazil regarding the association of MRS and self-evaluation variables, such as number of children, number of previous relationship and Socioeconomic Status (SES). The current literature has reported that individuals with children perform MRS more often than individuals with no children (Barbaro, Shakelford, Weeks-Shakelford, 2016), and SES has been found to be associated with satisfaction and stability of romantic relationships 
in adult life (for a review, see Conger, Conger, \& Martin, 2010), and partner violence (a modality of MRS) against women (Vyas \& Heise, 2016). Such variables could be contributing to the cross-cultural differences found in this paper. Future research controlling for these variables would clarify whether the differences between our samples are due to cultural differences or whether other sources of influence may have been overlooked. In Brazil, recruiting participants from different regions and comparing their MRS would also help to clarify if the cultural differences across the Brazilian states also affect how individuals preserve their relationships in this country.

Overall, our initial findings suggest the frequency of different strategies to maintain relationships vary across cultures and that culture alters the influence that variables such as facial attractiveness disparity and mate value have on MRS. More broadly, these results can be explained based on social and evolutionary theories, contributing to the integration of evolutionary and social psychology to provide a broader understanding of behaviour in relationships.

\section{References}

Barbaro, N., Pham, M. N., \& Shackelford, T. K. (2015). Solving the problem of partner infidelity: Individual mate retention, coalitional mate retention, and in-pair copulation frequency. Personality and Individual Differences, 82, 67-71. doi: 10.1016/j.paid.2015.02.033

Barbaro, N., Pham, M. N., Shackelford, T. K., \& Zeigler-Hill, V. (2015). Insecure romantic attachment dimensions and frequency of mate retention behaviors. Personal Relationships, 23(3), 605-618. doi: 10.1111/pere.12146 
Barbaro, N., Shackelford, T. K., \& Weekes-Shackelford, V. A. (2016). Mothers and fathers perform more mate retention behaviors than individuals without children. Human nature, 27(3), 316-333. doi: 10.1007/s12110-016-9261-z

Buss, D. M. (1988). From vigilance to violence: Tactics of mate retention in American undergraduates. Ethology and Sociobiology, 9, 291-317. doi: 10.1016/0162$\underline{3095(88) 90010-6}$

Buss, D. M., \& Duntley, J. D. (2013). The evolution of intimate partner violence. Aggression and Violent Behavior, 16(5), 411-419. doi: 10.1016/j.avb.2011.04.015

Buss, D. M., \& Shackelford, T. K. (1997). From vigilance to violence: mate retention tactics in married couples. Journal of Personality and Social Psychology, 72, 346361. doi: $\underline{10.1037 / 0022-3514.72 .2 .346}$

Buss, D. M., Shackelford, T. K., \& McKibbin, W. F. (2008). The mate retention inventory-short form (MRI-SF). Personality and Individual Differences, 44, 322334. doi: 10.1016/j.paid.2007.08.013

Buunk, B. P., Angleitner, A., Oubaid, V., \& Buss, D. M. (1996). Sex differences in jealousy in evolutionary and cultural perspective: Tests from the Netherlands, Germany, and the United States. Psychological Science, 7(6), 359-363. doi: 10.1111/j.1467-9280.1996.tb00389.x

Croucher, S. M., Homsey, D., Guarino, L., Bohlin, B., Trumpetto, J., Izzo, A., ... \& Sykes, T. (2012). Jealousy in Four Nations: A Cross-Cultural Analysis. Communication Research Reports, 29(4), 353-360. doi: $10.1080 / 08824096.2012 .723273$

Daly, M., Wilson, M., \& Weghorst, S. J. (1982). Male sexual jealousy. Ethology and Sociobiology, 3(1), 11-27. doi: $\underline{\text { 10.1016/0162-3095(82)90027-9 }}$ 
Davies, A. P., \& Shackelford, T. K. (2017). Don't you wish your partner was hot like me?: The effectiveness of mate poaching across relationship types considering the relative mate-values of the poacher and the partner of the poached. Personality and Individual Differences, 106, 32-35. doi: 10.1016/j.paid.2016.10.029

Dillon, L., Nowak, N., Shattuck, K., Weisfeld, G., Weisfeld, C., Imamoğlu, E., ... \& Jiliang, S. (2014). When the cat's away, the spouse will play: a cross-cultural examination of mate guarding in married couples. Journal of Evolutionary Psychology, 12(2-4), 97-108. doi: 10.1556/JEP-D-13-00003

Hatfield, E., \& Rapson, R. L. (2006). Passionate love, sexual desire, and mate selection: Cross-cultural and historical perspectives. Close relationships: Functions, forms and processes, 227-243. Retrieved from http://www.elainehatfield.com/uploads/3/4/5/2/34523593/80._hatfield_rapson_2 006.pdf

Hofstede, G. (1984). Culture's consequences: International differences in work-related values. Beverly Hills: Sage Publications.

Holden, C. J., Shackelford, T. K., Zeigler-Hill, V., Miner, E. J., Kaighobadi, F., Starratt, V. G., ... \& Buss, D. M. (2014). Husband's esteem predicts his mate retention tactics. Evolutionary Psychology, 12(3), 655-672. doi:

$\underline{10.1177 / 147470491401200311}$

Hutz, C. S., \& Zanon, C. (2011). Revisão da apadtação, validação e normatização da escala de autoestima de Rosenberg: Revision of the adaptation, validation, and normatization of the Roserberg self-esteem scale. Avaliação Psicológica, 10(1), 41-49. Retrieved from http://www.redalyc.org/html/3350/335027285005/

Kemer, G., Çetinkaya, Y. E., \& Bulgan, G. (2016). Emotional Dependency and Dysfunctional Relationship Beliefs as Predictors of Married Turkish Individuals' 
Relationship Satisfaction. The Spanish Journal of Psychology. doi:

$\underline{10.1017 / \mathrm{sjp} .2016 .78}$

Kenrick, D. T., Trost, M. R. (2004). Evolutionary approaches to relationships. In H. T.

Reis \& C. E. Rusbult (Eds.), Close relationships: Key readings (pp. 115-131).

New York, NY: Psychology Press.

Landolt, M. A., Lalumière, M. L., \& Quinsey, V. L. (1995). Sex differences in intra-sex variations in human mating tactics: An evolutionary approach. Ethology and Sociobiology, 16, 3-23. doi: 10.1016/0162-3095(94)00012-V

Lopes, G. S., Shackelford, T. K., Santos, W. S., Farias, M. G., \& Segundo, D. S. (2016). Mate retention inventory-short form (MRI-SF): Adaptation to the Brazilian context. Personality and Individual Differences, 90, 36-40. doi: 10.1016/j.paid.2015.10.033

Miguel, A. de \& Buss, D. M. (2011). Mate retention tactics in Spain: Personality, sex differences, and relationship status. Journal of Personality, 79, 563-586. doi: 10.1111/j.1467-6494.2011.00698.x

Miner, E. J., Starratt, V. G., \& Shackelford, T. K. (2009). It's not all about her: Men's mate value and mate retention. Personality and Individual Differences, 47(3), 214-218. doi: 10.1016/j.paid.2009.03.002

Næss, S., Blekesaune, M., \& Jakobsson, N. (2014). Marital transitions and life satisfaction Evidence from longitudinal data from Norway. Acta Sociologica, 58,63-78. doi: $\underline{10.1177 / 0001699314563841}$

Nowak, N., \& Danel, D. (2014). Mate value asymmetry and relationship satisfaction in female opinion. Journal of sex \& marital therapy, 40(5), 425-433. doi: $\underline{10.1080 / 0092623 X .2012 .756839}$ 
Oltmanns, J. R., Markey, P. M., \& French, J. E. (2017). Dissimilarity in physical attractiveness within romantic dyads and mate retention behaviors. Journal of Social and Personal Relationships, 34(4), 565-577. doi:

\section{$\underline{10.1177 / 0265407516647203}$}

Pham, M.N., \& Shackelford, T.K. (2013). Oral sex as mate retention behavior. Personality and Individual Differences, 55, 185-188. doi: $\underline{10.1016 / j . p a i d .2013 .02 .012}$

Pham, M.N., Shackelford, T.K., \& Sela, Y. (2013). Women's oral sex behaviors and risk of partner infidelity. Personality and Individual Differences, 55, 446-449. doi: $\underline{10.1016 / j . p a i d .2013 .04 .008}$

Pollet, T., \& Saxton, T. (2018). How diverse are the samples used in the journals 'Evolution \& Human Behavior' and 'Evolutionary Psychology'?. http://doi.org/10.17605/OSF.IO/7H24P

Rosenberg, M. (1965) The measurement of self-esteem: Society and the Adolescent Self Image. Princeton University, NJ, Princeton University Press.

Salkicevic, S., Stanic, A. L., \& Grabovac, M. T. (2014). Good mates retain us right: Investigating the relationship between mate retention strategies, mate value, and relationship satisfaction. Evolutionary Psychology, 12(5), 1038-1052. doi: $10.1177 / 147470491401200512$

Schmitt, D. P. (2004). Patterns and Universals of Mate Poaching Across 53 Nations: The Effects of Sex, Culture, and Personality on Romantically Attracting Another Person's Partner. Journal of Personality and Social Psychology, 86, 560-584. doi: 10.1037/0022-3514.86.4.560 
Schmitt, D. P. (2005). Sociosexuality from Argentina to Zimbabwe: A 48-nation study of sex, culture, and strategies of human mating. Behavioral and Brain Sciences, 28(02), 247-275. doi: 10.1017/S0140525X05000051

Schmitt, D. P., Alcalay, L., Allensworth, M., Allik, J., Ault, L., Austers, I., ... \& Braeckman, J. (2004). Patterns and universals of adult romantic attachment across 62 cultural regions: Are models of self and of other pancultural constructs?. Journal of Cross-Cultural Psychology, 35(4), 367-402. doi: $\underline{10.1177 / 0022022104266105}$

Sidelinger, R. J., \& Booth-Butterfield, M. (2007). Mate value discrepancy as predictor of forgiveness and jealousy in romantic relationships. Communication Quarterly, 55(2), 207-223. doi: 10.1080/01463370701290426

Starratt, V. G., Shackelford, T. K., Goetz, A. T., \& McKibbin, W. F. (2007). Male mate retention behaviors vary with risk of partner infidelity and sperm competition. Acta Psychologica Sinica, 39, 523-527.

Triandis, H. C. (2018). Individualism and collectivism. Boulder, CO: Westview Press.

Vyas, S., \& Heise, L. (2016). How do area-level socioeconomic status and gender norms affect partner violence against women? Evidence from Tanzania. International journal of public health, 61(8), 971-980. doi: 10.1007/s00038-016-0876-y

Zeigler-Hill, V., Fulton, J. J., \& McLemore, C. (2012). Discrepancies between Explicit and Implicit Self-Esteem: Implications for Mate Retention Strategies and Perceived Infidelity. The Journal of Social Psychology, 152, 670-686. doi: $10.1080 / 00224545.2012 .688778$ 


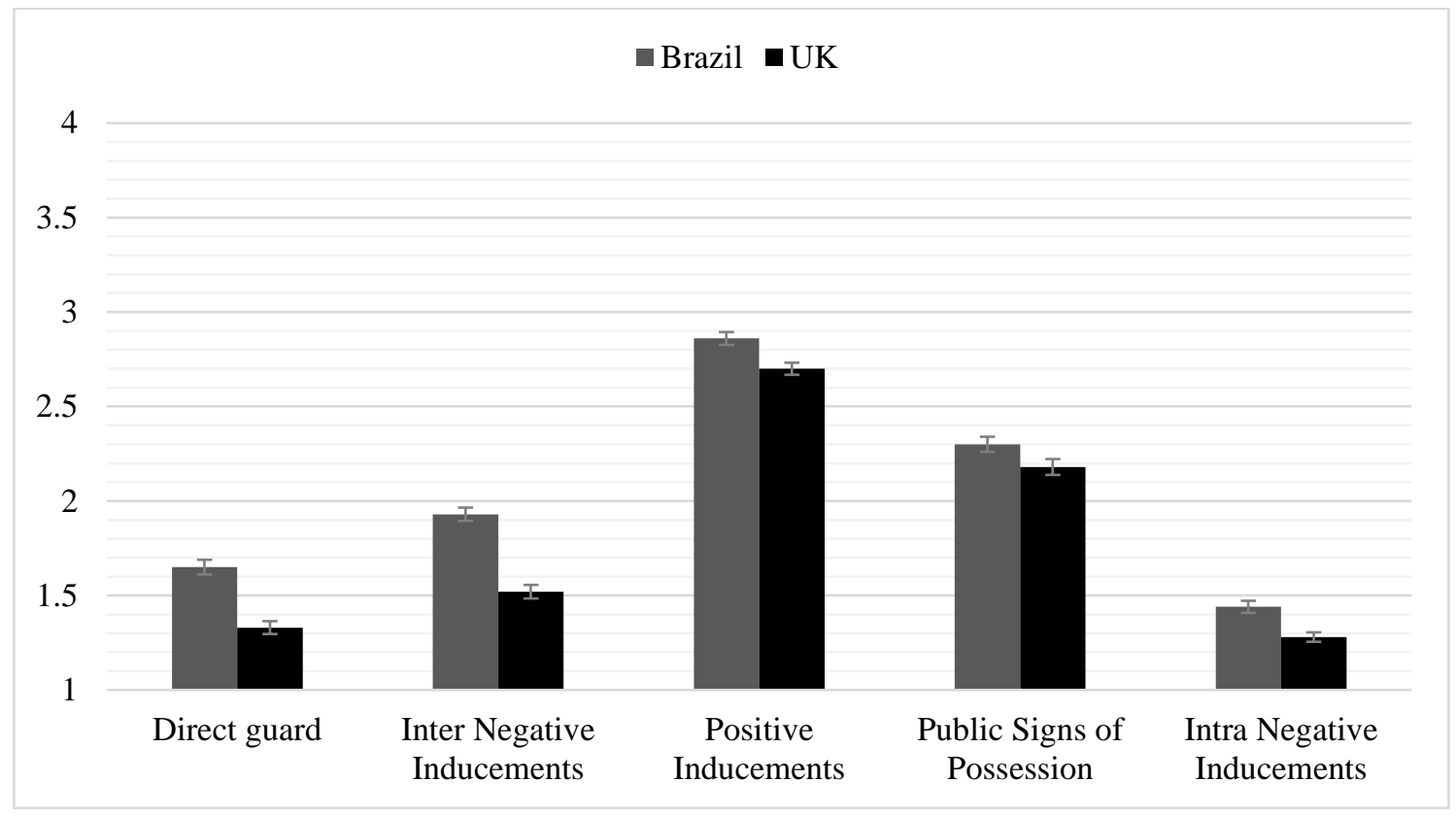

Figure 1. MRS of women in Brazil and in the UK. Values represent the mean and error bars indicate SE 


\section{Table 1}

Correlations between self-evaluation variables and MRS in Brazilian and British men

\begin{tabular}{|c|c|c|c|c|c|c|c|c|}
\hline & $\begin{array}{l}\text { Direct } \\
\text { guard }\end{array}$ & $\begin{array}{c}\text { Intersexual } \\
\text { negative } \\
\text { Inducements }\end{array}$ & $\begin{array}{c}\text { Positive } \\
\text { inducements }\end{array}$ & $\begin{array}{l}\text { Public signals } \\
\text { of possession }\end{array}$ & $\begin{array}{c}\text { Intrasexual } \\
\text { negative } \\
\text { Inducements }\end{array}$ & $\begin{array}{c}\text { Self- } \\
\text { esteem }\end{array}$ & $\begin{array}{l}\text { Mate } \\
\text { value }\end{array}$ & $\begin{array}{c}\text { Attractiveness } \\
\text { disparity }\end{array}$ \\
\hline Direct guard & & $.67^{* *}$ & .26 & $.39^{* *}$ & $.79^{* *}$ & -.21 & -.07 & -.03 \\
\hline Intersexual negative & & & & & & & & \\
\hline Inducements & $.49^{* *}$ & & $.37^{*}$ & $.53^{* *}$ & $.82^{* *}$ & -.09 & -.07 & .10 \\
\hline $\begin{array}{c}\text { Positive } \\
\text { inducements }\end{array}$ & $.30^{*}$ & .23 & & $.53^{* *}$ & .09 & -.16 & -.17 & -.22 \\
\hline $\begin{array}{c}\text { Public signals of } \\
\text { possession }\end{array}$ & .17 & $.43^{* *}$ & $.52^{* *}$ & & $.41^{* *}$ & -.04 & $-.29^{*}$ & .06 \\
\hline Intrasexual negative & & & & & & & & \\
\hline & $.44^{* *}$ & $.46^{* *}$ & .27 & $.37^{* *}$ & & -.16 & -.03 & .21 \\
\hline Self-esteem & -.27 & -.22 & .06 & -.08 & -.20 & & .29 & .23 \\
\hline Mate value & -.28 & -.13 & .16 & .05 & -.13 & .20 & & $.62^{* *}$ \\
\hline $\begin{array}{c}\text { Attractiveness } \\
\text { disparity }\end{array}$ & -.12 & .07 & -.12 & -.06 & $-.39^{* *}$ & .11 & -.08 & \\
\hline
\end{tabular}

Note. Correlations for Britons are displayed above the diagonal, while Brazilian sample correlations are displayed in the lower diagonal. $* * p<.001 ; * p<.01$. 
Table 2

Correlations between self-evaluation variables and MRS in Brazilian and British women

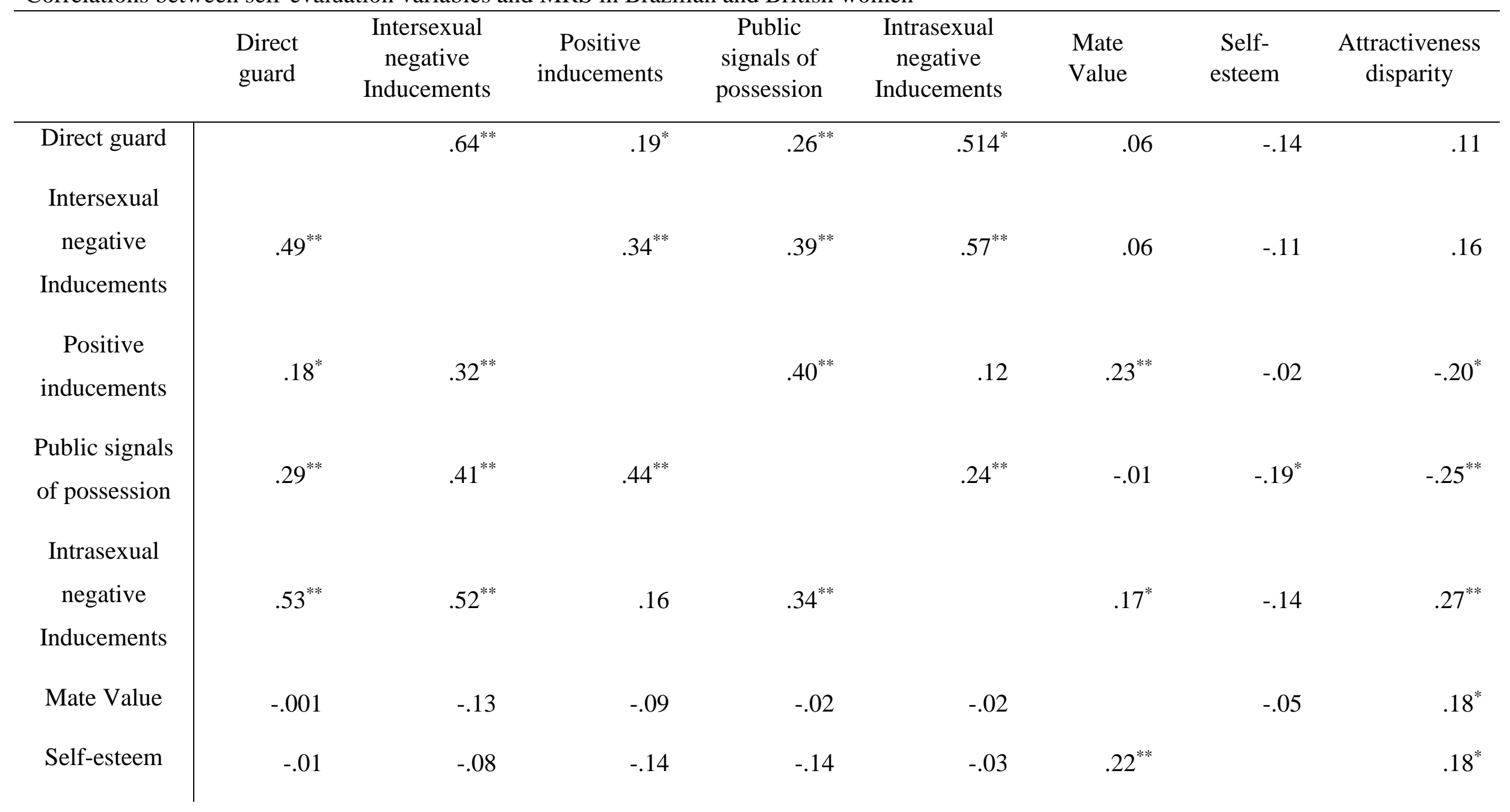




\begin{tabular}{c|lllllll} 
Attractiveness & & & & & & \\
disparity & -.03 & -.09 & .00 & -.09 & -.00 & $.26^{* *}$
\end{tabular}

Note. Correlations for British women are displayed above the main diagonal, while correlations for Brazilian women are displayed below the main diagonal. $* * p<.001 ; * p<.05$ 
Annex I

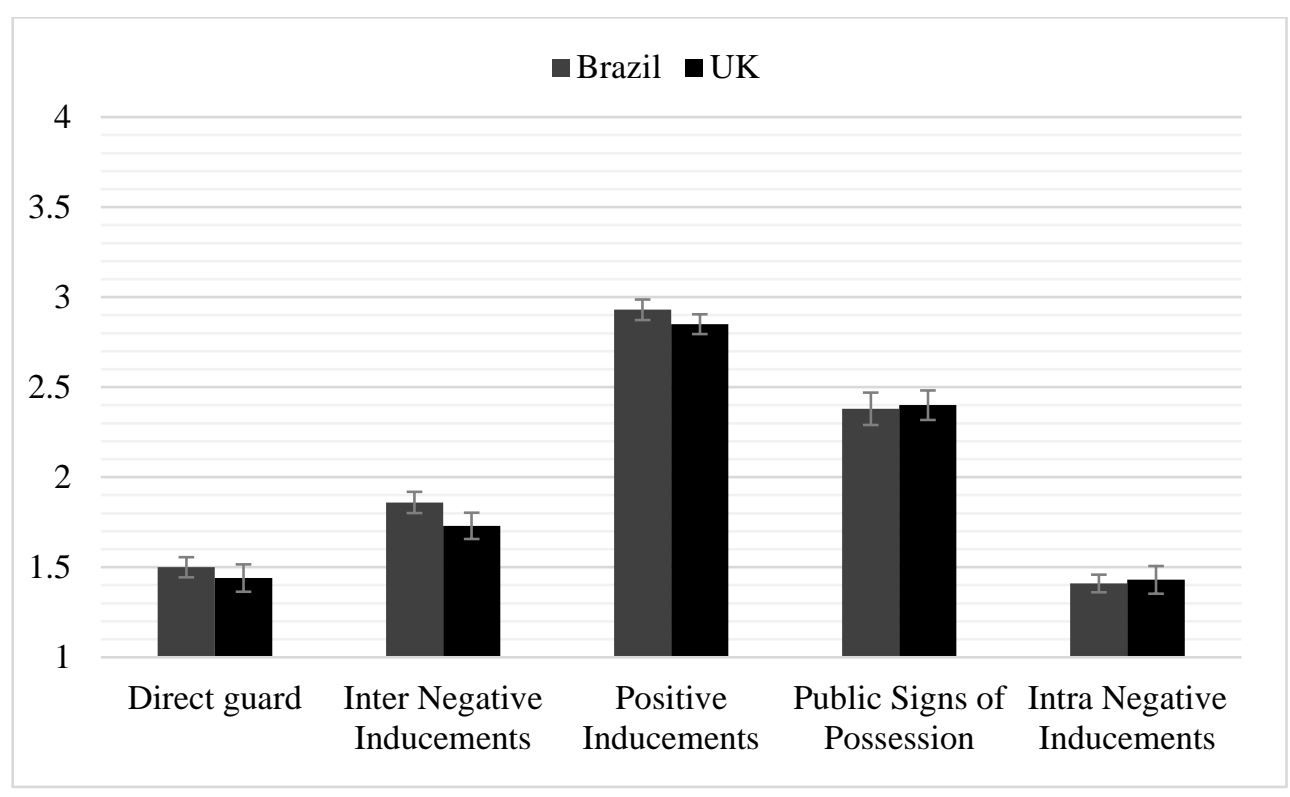

Figure 2. MRS of men in Brazil and in the UK. Values represent the mean and error bars indicate SE 
Annex II

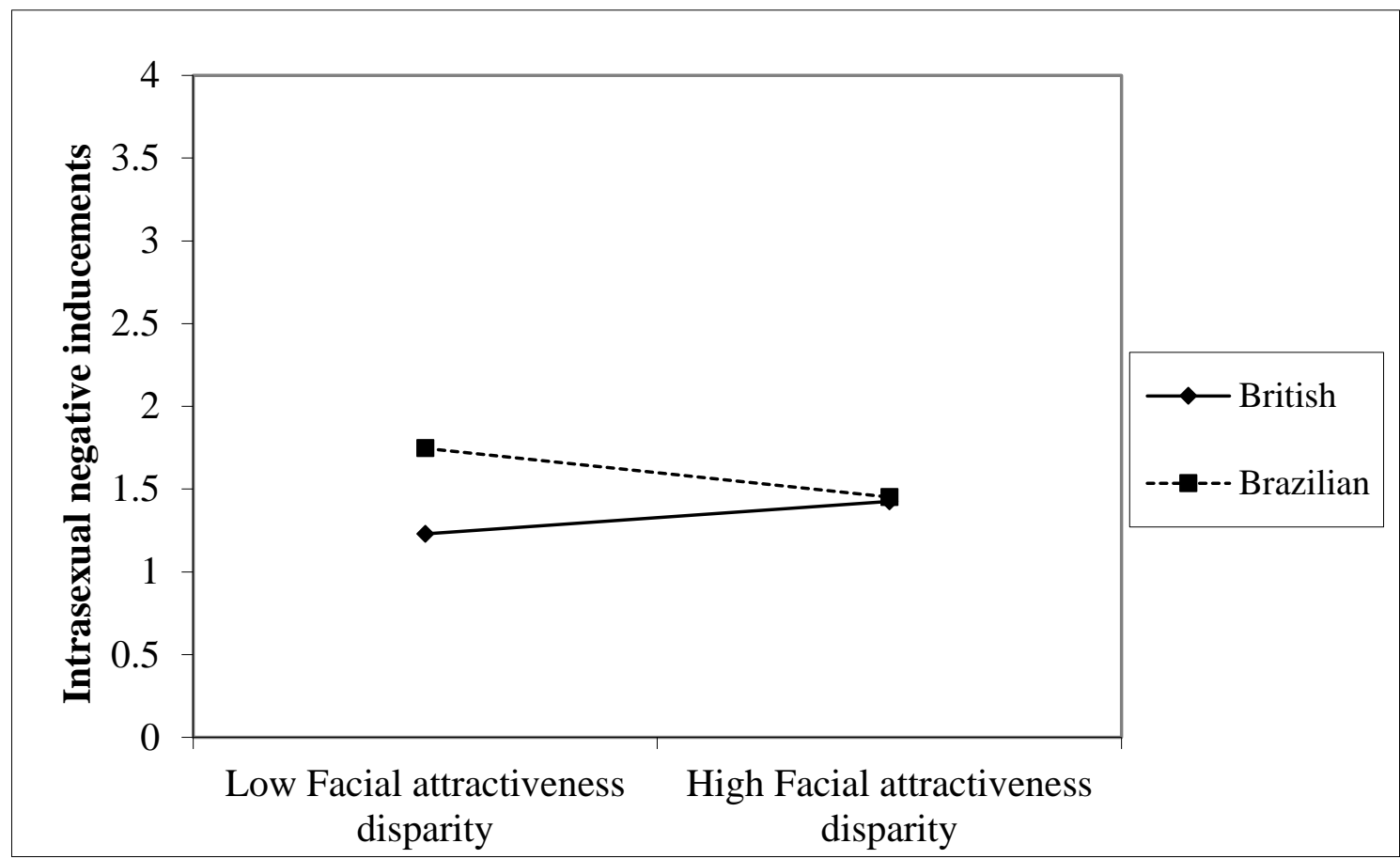

Figure 3. Interaction effect of facial attractiveness disparity and culture on intrasexual negative inducements among men. 
Annex III

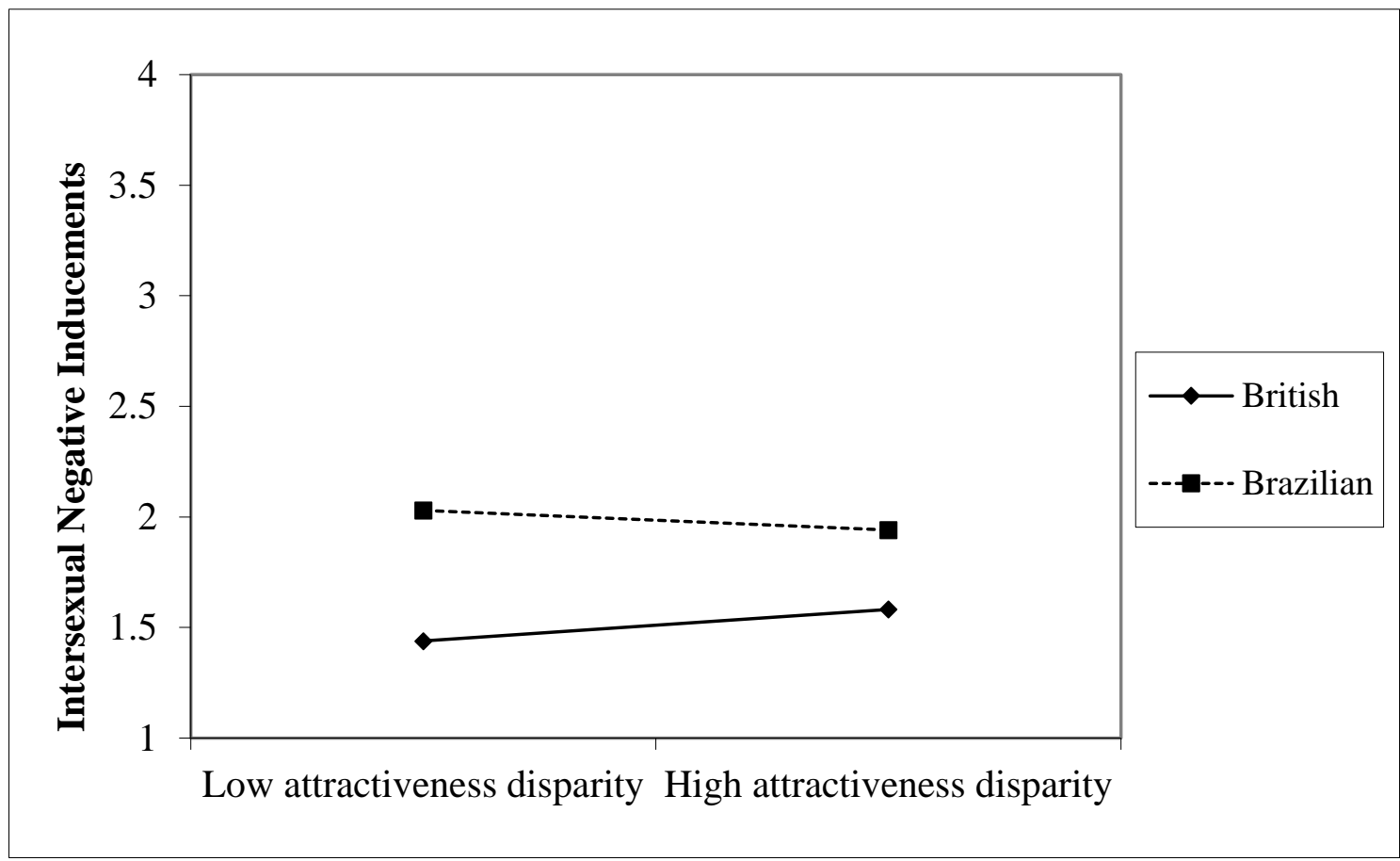

Figure 4. Interaction effect of facial attractiveness disparity and culture on intersexual negative inducements 
Annex IV

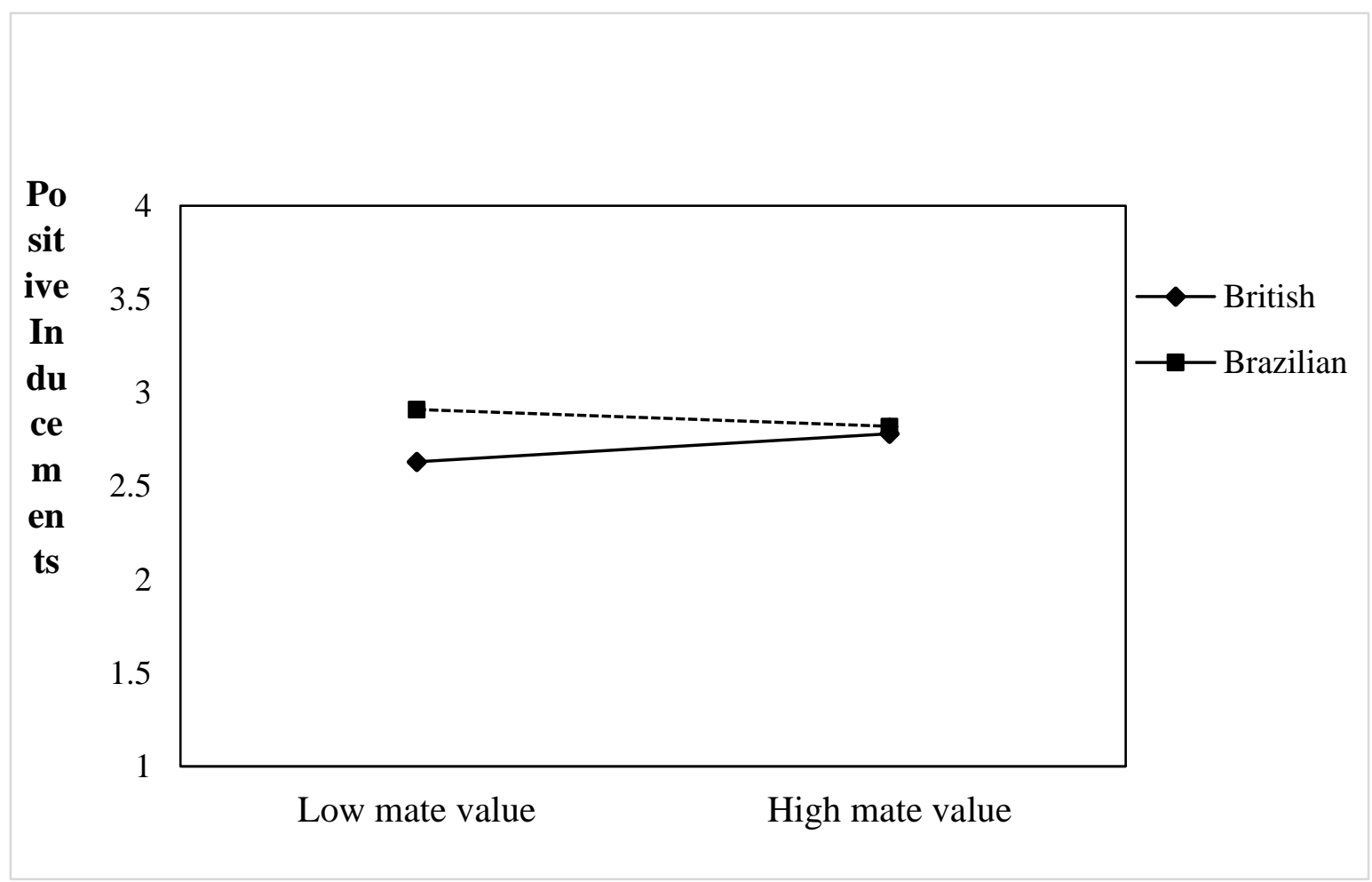

Figure 5. Interaction effect of mate value and culture on positive inducements 
Annex V

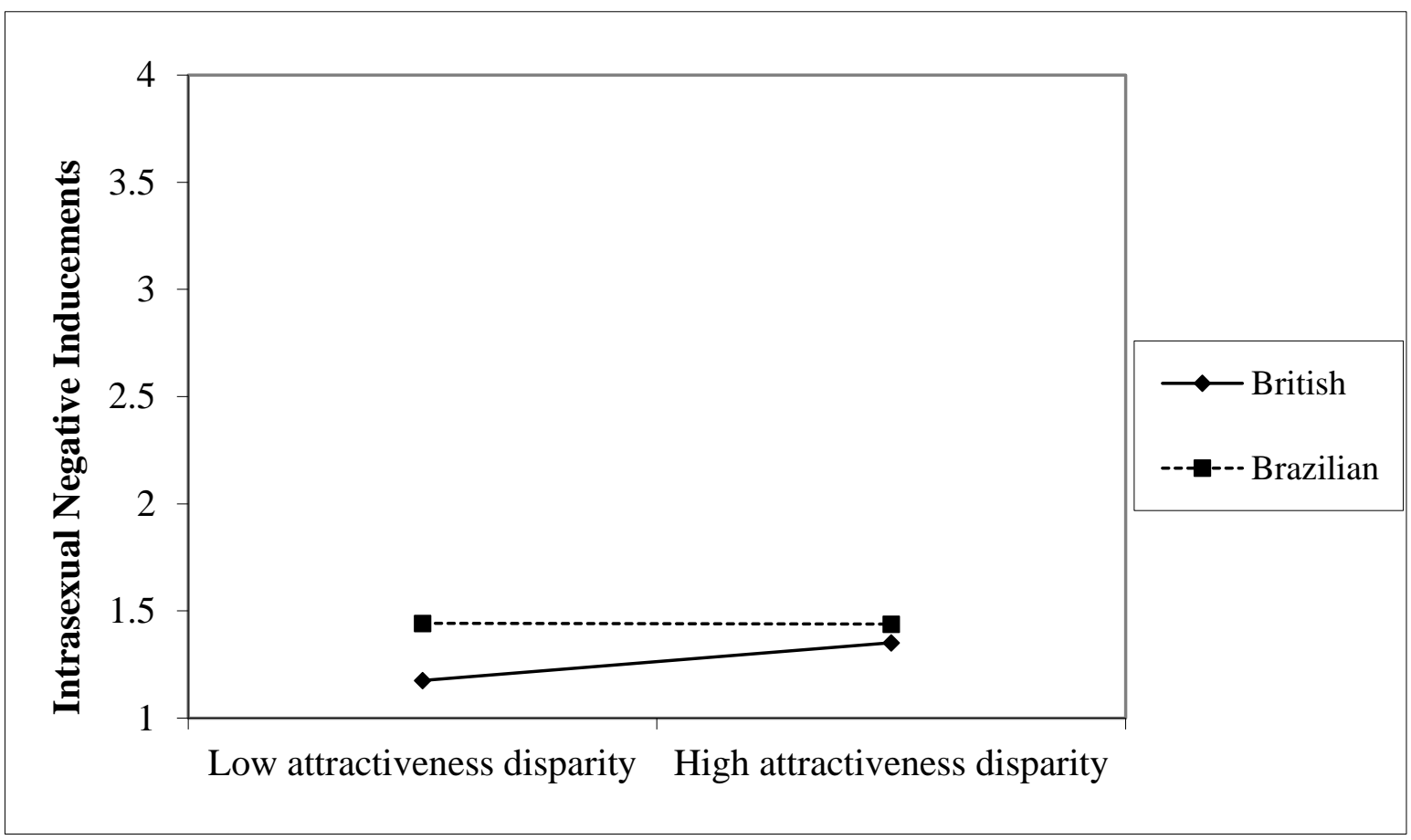

Figure 6. Interaction effect of FAD and culture on intrasexual negative inducements 
